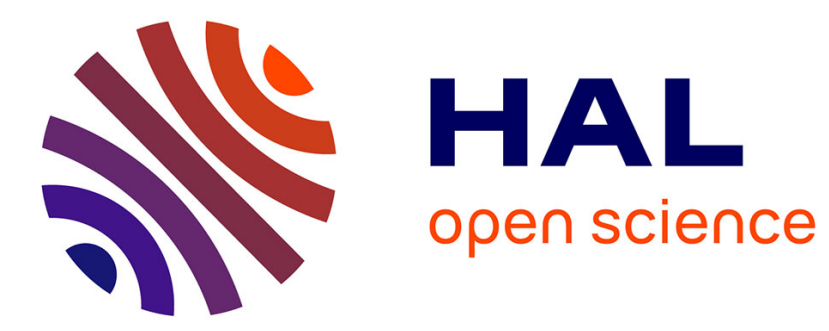

\title{
Sheet nacre growth mechanism: a Voronoi model.
}

Marthe Rousseau, Evelyne Lopez, Alain Couté, Gérard Mascarel, David C. Smith, Roger Naslain, Xavier Bourrat

\section{To cite this version:}

Marthe Rousseau, Evelyne Lopez, Alain Couté, Gérard Mascarel, David C. Smith, et al.. Sheet nacre growth mechanism: a Voronoi model.. Journal of Structural Biology, 2005, 149 (2), pp.149-57. 10.1016/j.jsb.2004.09.005 . hal-00131385

\section{HAL Id: hal-00131385 \\ https://hal.science/hal-00131385}

Submitted on 21 Nov 2007

HAL is a multi-disciplinary open access archive for the deposit and dissemination of scientific research documents, whether they are published or not. The documents may come from teaching and research institutions in France or abroad, or from public or private research centers.
L'archive ouverte pluridisciplinaire HAL, est destinée au dépôt et à la diffusion de documents scientifiques de niveau recherche, publiés ou non, émanant des établissements d'enseignement et de recherche français ou étrangers, des laboratoires publics ou privés. 


\title{
Sheet nacre growth mechanism: a Voronoi model
}

\author{
Marthe Rousseau $^{\mathrm{a},}$, Evelyne Lopez ${ }^{\mathrm{a},}$, Alain Coutéb, , Gérard Mascarel ${ }^{\mathrm{b},}$, David C. \\ Smith $^{\mathrm{c},}$, Roger Naslain ${ }^{\mathrm{d},}$ and Xavier Bourrat ${ }^{\mathrm{d}, \mathrm{e}}$ \\ ${ }^{a}$ Museum National d'Histoire Naturelle, Département des Milieux et Peuplements Aquatiques \\ UMR 5178: CNRS-MNHN: Biologie des Organismes Marins et Ecosystémes 7, rue Cuvier \\ 75005, Paris, France \\ ${ }^{\mathrm{b}}$ Museum National d'Histoire Naturelle, Département Régulations, Développement et \\ Diversité Moléculaire USM 505 Ecosystémes et Interactions toxiques 12, rue Buffon 75005, \\ Paris, France \\ ${ }^{\mathrm{c}}$ Museum National d'Histoire Naturelle, Département de l'Histoire de la Terre, USM 205 \\ Laboratoire d'Etude de la Matiére Extraterrestre 61, rue Buffon 75005 Paris FRANCE, UMR \\ 7072 Tectonique, Université Paris VI, 4 place Jussieu 75005, Paris, France \\ ${ }^{\mathrm{d}}$ Université Bordeaux 1, LCTS 3, allée de la Boétie, 33600 Pessac, France \\ E ISTO, Institut des Sciences de la Terre d'Orléans, CNRS-INSU / Université d'Orléans, \\ UMR 6113, Rue de Saint-Amand Bâtiment Géosciences BP 675945067 Orléans Cedex 2
}

\begin{abstract}
Shell nacre (mother of pearl) of Pinctada margaritifera was analyzed by scanning electron microscopy. The originality of this work concerns the sampling performed to observe incipient nacre on the mantle side. The whole animal is embedded in methyl methacrylate followed by separation of the shell from the hardened mantle. It is revealed this way how each future nacre layer pre-exists as a film or compartment. Experimental observations also show for the first time, the progressive lateral crystallization inside this film, finishing under the form of a non-periodic pattern of polygonal tablets of bio-aragonite. It is evidenced that nuclei appear in the film in the vicinity of the zone where aragonite tablets of the underlying layer get in contact to each other. A possible explanation is given to show how nucleation is probably launched in time and space by a signal coming from the underlying layer. Finally, it is evidenced that tablets form a Voronoi tiling of the space: this suggests that their growth is controlled by an "aggregation-like" process of "crystallites" and not directly by the aragonite lattice growth.
\end{abstract}

Keywords: Mother of pearl; Structure; Bio-mineralization; Organic matrix; Mechanism; SEM 


\section{Introduction}

The active role of the organic matrix and especially that of proteins in bio-mineralization is fundamental (Belcher et al., 1996, Falini et al., 1996 and Feng et al., 1999); it represents a source of inspiration for future nanotechnology with a bottom-up approach. The "brick and mortar" ordering of nacre (mother of pearl) has already inspired the toughening of ceramic materials by co-processing rigid ceramic as silicon carbide and compliant interlayers as boron nitride (Naslain et al., 1998 and Smith, 1998) and many other examples (Simkiss and Wilbur, 1989).

The interdigitating brickwork array of tablets of sheet nacre, is not the only interesting aspect of nacre structure. The bio-crystal itself is a composite. It has not only the mineral structure of aragonite but possesses an intracrystalline organic content (Schmidt, 1924, Watabe, 1965 and Weiner and Traub, 1984) occluded or having a role of organic template (Wada, 1972) already evidenced by in vitro experiments.

The long range orientation from layer to layer is another intriguing feature to understand. The spatial organization of the bio-mineralization mechanism of the crystal growth is the main focus of the present paper. The original idea is to harden the soft tissues whilst maintaining intact the interface with the hard mature nacre. A direct vision of the mineralization zone yields information on the phenomena taking place during the bio-mineralization.

\section{Experimental conditions}

\subsection{Preparation of growing shell surfaces (protocol 1)}

A six months old Pinctada margaritifera oyster, maintained at a depth of 7-12 $\mathrm{m}$ in French Polynesia, was sacrificed. It was fixed in $70 \%$ ethanol, then dehydrated very progressively and finally the fat was removed with xylene. At this stage the oyster was embedded in methyl methacrylate. Some sections were cut across the animal (100 $\mu$ m thick). Then, the shell was removed as shown in Fig. 1. The mantle tissues are hardened by the preparation. Such that the removal of the shell permits the analysis of a fracture propagation in-between the hardened tissues and the shell. What is shown in Fig. 2 and Fig. 3 is the fracture surface, on the mantle side, after the removing of the mature nacre layer previously stuck on it (observation following empty arrows in Fig. 1B). Then, the other side of this fracture surface was studied in detail with the complementary sequence: i.e., the side of the shell (Fig. 4, Fig. 5, Fig. 6, Fig. 7 and Fig. 8).

\subsection{Direct observation of the hard part of the shell (protocol 2)}

A second type of observation can be qualified as a direct observation of the nacre surface. In this case, the animal is dipped alive in alcohol. At the laboratory, the soft tissues are gently removed from the shell which is dried, gold coated and then analyzed by SEM (second protocol). This sampling can be applied only on the shell (Fig. 9 and Fig. 10), the mantle cannot be observed in this way. Artefacts related to each experimental protocol will be discussed with the results. 


\subsection{SEM examination}

Observations with SEM were made systematically after gold coating on the JEOL JSM-840A of the Common Service of Electronic Microscopy of the laboratories of the Life Sciences (Museum National d'Histoire Naturelle). A Hitachi 4500 FEG was also used at lower voltage for some more details.

\subsection{Raman spectroscopy}

Specimens for Raman microscopy were analyzed as following with a DILOR XY spectrometer: objective 50×; green argon laser excitation at $514.5 \mathrm{~nm}$ laser power at source: 100-200 mW; CCD multichannel detection in the range of $130-1200 \mathrm{~cm}^{-1}$; slit width 100 $150 \mu \mathrm{m} ; 5$ counts of $20 \mathrm{~s}$ and peak position calibration corrected to standard diamond at $1332 \mathrm{~cm}^{-1}$.

\section{Results: bio-mineralization sequence observed on mantle side}

Contrary to usual SEM observations, Fig. 2 gives a vision of the growing nacre layers but on the side of the epithelial tissue. After fixation, dehydration and mounting of the whole animal, the shell was removed from the animal (fixed and hardened by the preparation). Thus what is shown in Fig. 2 is a plane view of the mantle surface, after the removal of the mature nacre layer. This side will be referred to as mantle side in the following. As far as is known, it is the first time that plane sections of the growing front of nacre are imaged. The opposite side, removed from the animal, is the shell covered with the mature nacre. It will be referred to as the shell side. It is this side which provides the regular SEM pictures usually produced in the literature.

\subsection{Interface in-between hard and soft tissues}

It is important to note first that this SEM preparation is a fracture surface. In other words, the surface which is observed in Fig. 2 results from the crack propagation produced by the removal of the mineral shell at the end of the preparation. The crack has separated the hardened tissues of the mantle from the mature nacre.

The first comment concerns the way the fracture propagates at the interface. Most of the time the crack propagates parallel to the layering in the interlaminar matrix, but this crack is very regularly deflected to the next interlaminar zone. It can be seen that the location of the deflection corresponds systematically to the zone where the film contains a critical amount of white round tablets. This can be interpreted as a region with a higher rigidity (critical volume fraction of rigid filler (tablets) in the more supple film). The result is the "garden terrace" appearance revealed by this fracture referred to here as the "stairs-like" front of the biomineralization in sheet nacre.

The second point concerns the critical examination of the experimental data to evidence possible artefacts introduced by the protocol of mounting. What is not known is the role of the embedding medium in the observed features. No doubt about the mineral reality of the white round tablets that appear. Raman will confirm their crystallized state. It can also be stated that the sharpness and reproducibility of the fine organic features described below, imply their pre-existence before the embedding. It has never been reported that MMC embedding has, 
anytime, created such features by reaction with the organic matrix. Thus they can be safely interpreted as part of the bio-mineralization process. A doubt arises concerning the nature of the featureless volumes inside the compartments: are they liquids or gels, partially or completely replaced by the MMC? Before mounting, they cannot be a solid nor even a gas. The simpler hypothesis to postulate is that the film is shaped under the form of a liquid more or less viscous. This "viscous" medium further hardens during mounting without any precision about its original state and composition.

Having said that, many observations can be safely made about Fig. 2 and Fig. 3, as following (Fig. 3 is a high magnification focused on two stairs).

\subsection{The stairs-like growing front in sheet-nacre}

First, this fracture surface confirms that nacre growth does not occur layer after layer; all the layers are growing at the same time. Each step is a growing layer front with a spatial offset compared to its neighbors (above and below) with a critical distance from one step to the other. A given row grows from one side of the shell to the other, at the same time.

Then, the inspection of this preparation shows us that each future layer pre-exists under the form of a film. Each film or compartment is very soon individualized from its neighbors, i.e., the raw below also called the underlying row (the row more matured) and above (the one less matured). The secretion zone of fluid is not visible. A cross section is to be applied. Anyway, a viscous fluid is necessary to shape the compartment and define its thickness (stage i).

A progressive crystallization within this film can be seen. It can be rationalize as follow by a lateral inspection starting from the epithelium, to the mature nacre: (i) the shaping of the film (compartment); (ii) nucleation of round tablets of aragonite; (iii) growth of cylindrical tablets, and (iv) their progressive transformation into polygons up to the complete bio-crystallization of the layers (v) (the two last steps are visible on the other side, Fig. 4, Fig. 5, Fig. 6, Fig. 7 and Fig. 8, and will be described below).

\subsection{Nucleation signal}

The nuclei are located at the level where the intercrystalline matrix of the underlying layer forms, that is to say when tablets of the underlying layer get into contact (arrows in Fig. 3). This experimental evidence is based on the fact that the film registers and displays the imprints of the rigid tablets already nearly developed, those of the underlying row. More precisely the imprints mark the periphery of the tablets as will be confirmed by the observations on shell side. This is evidenced for the first time.

Note that these imprints that form at the surface of the film disappear at the completion of the tablets in the underlying layer (Fig. 3, right hand side). These imprints are likely to compose the disclosure of close relationships from one step to the other. They correspond to the zone of maximum activity: the zone of mineralization. It is suspected that mater is exchanged from one floor to the other: e.g., water in one direction and components of mineral species in the other. When the mineralization of the step is completed, the imprints disappear supposedly, because only insoluble matter is left in the intercrystalline zone. 


\section{Results: mineralization of the compartment (film) as seen from the shell side}

\subsection{Growth of aragonite tablets}

Fig. 4, Fig. 5, Fig. 6, Fig. 7 and Fig. 8 are the main features observed by SEM on the opposite side, i.e., the shell side. With these additional observations, it is possible to evidence the remainder of the series of bio-mineralization stages, i.e., platelets growing up to mature nacre.

In Fig. 4, we find again the film and the isolated round growing tablets. It is worthy of note that aragonite tablets first acquire their final thickness and then laterally extend with a cylindrical shape until they become in contact with each other. At that stage, the film becomes residual and the tablets acquire a polygonal shape. Most of the time the surface is covered by a thin coating which remains stuck on this side.

Several interesting details are related to the imprints of nuclei on the shell side. Contrary to the imprints seen previously on the mantle side, they mark the entire surface of the incipient aragonite platelets (Fig. 5). Note that the platelets are seen on their other face. Fig. 6 is an enlargement of one of these imprints: the trace is centered on a vertex at the boundary of three polygonal tablets of the underlying layer. Generally it is in-between two tablets or even centered inside the tablet (rare). Nucleation and lateral extension of the tablets start with the deposit of this holy thin membrane at the surface of the underlying layer and forming the imprints. Growth cannot proceed without the previous deposit of what is supposed to be a "structural organic matrix." In Fig. 6 and Fig. 7 it can be seen that the imprints are featured with alveoli. The continuity with the intercrystalline organic matrix from the underlying row can be postulated, based on evidences as those of Fig. 7: this alveolar matrix could constitute the signal for starting nucleation.

\subsection{Raman characterization of aragonite nuclei}

Fig. 8A is a SEM view at high magnification of a growing step on the shell side. It is easy to distinguish aragonite tablets from the surrounding film at the same level, and polygonal mature aragonite on the underlying layer. The locations of two comparative Raman analyses are presented in (Fig. 8B). They were obtained on growing white tablets (star) and on the film in the surrounding area (circle). The two spectra exhibit the same characteristic peaks of aragonite. The film also shows the presence of significant fluorescence: a continuous background emission here increasing with wavenumber. High fluorescence in a Raman spectrum of a mineral can have various causes, e.g., (i) an emission due to a lack of good crystallinity (atoms that guide in the right place, or atomic vacancies); (ii) the presence of organic matter in the form of living multicellular organisms with innumerable different molecules in each cell, or of dead delaying multicellular organism, or of decaying non-cellular organic molecules; (iii) the presence of trace elements like $\mathrm{Mn}^{2+}$ or $\mathrm{Fe}^{3+}$ replacing $\mathrm{Ca}^{2+}$ in carbonate but there usually give to substantial coloration. In these spectra, (ii) is by far the most probable cause, (i) being less likely since the Raman bands are not wider in the film than in the nucleus as would be expected from structurally disordered crystals. It is supposed that fixing and drying the film precipitates nanocrystals of aragonite (preparation artifact). At least, these Raman spectra on the film indicate that MMC is not simply filling voids inbetween the tablets but hardening a present medium. The film is not easy to characterize without preparation artifacts. 


\subsection{Direct observation of the shell (second protocol)}

A second series of observations were made directly on the shell side after the removal of the soft tissues (their is no embedding in this second protocol).

With this second protocol, the shell is observed as it: most of the nuclei can still be seen, remaining on the shell side (Fig. 9).

Also, it can be seen that most of the film was solubilized in alcohol. Only a thin "coating" is left at the surface of the underlying row of mature nacre, with the nuclei stuck on it. (Below, in the underlying row, the residual film in-between the polygonal tablets is also completely solubilized with protocol two). Fig. 10 shows that the coating solubility changes in the neighborhood of the platelets: it is more "soluble" in those areas. This lack of matter around the nuclei is supposed to reveal a gradient of "soluble" species due to transport activities close to the growing periphery of the platelets.

A fibrous array appears beneath the crystals as a "cobweb" which forms the substrate for nucleation and further extension of the tablets. Its insolubility and its fibrous nature may be in line with the presence of $\beta$-chitin described in the median position by Levi-Kalisman et al. (2001) inside the interlaminar organic matrix.

\section{Modelization: Voronoi diagram as a model for tablet growth in the compartment}

For the first time the exact number of nuclei, their location and growth rate could be approached. Some dynamic aspects of nacre growth were quantified.

- The offset from one step to an other is under control. We measured a distance of 10-15 $\mu \mathrm{m}$ from one front to the other at the adult stage near the edge.

- A distance of $20-30 \mu \mathrm{m}$ is thus necessary for the complete mineralization of the film involving the following steps: (i) shaping of the film; (ii) nucleation; (iii) growth; and (iv) polygonization as a completely mature nacre layer, on the same step level.

- A growth rate of $3.4 \pm 1.4$ layers per day in the case of $P$. margaritifera's pearl was measured by Caseiro (1995). Thus, shaping of fluid and transformation into mature nacre can occur in approximately $7 \pm 2 \mathrm{~h}$. This is an average value for the South Pacific.

- SEM provides useful contrasts to locate nucleation and to measure its density within the film. As crystallization proceeds, nuclei appear with a brighter contrast in the film. Nucleation of new tablets has to stay well-controlled to be statistically constant in density: $\approx 11$ nuclei for $100 \mu \mathrm{m}^{2}$. This makes 1 nucleus for approximately $10 \mu \mathrm{m}^{2}$. Which is consistent with the mean size of the tablets in P. margaritifera. This confirms the observations of Wada (1972) on the location of nuclei on the inner sheet of the compartment as well as the singularity of the tablet nucleation (1 nucleus/tablet).

- SEM also confirms that they grow in all directions (Fig. 9) until they reach a cylindrical shape, extending under the form of round slice which becomes polygonal when getting in contact with adjacent ones. The mean thickness of the tablets is $300-500 \mathrm{~nm}$ while the extent is few micrometers. 
The question arises immediately about the fit with a simple Voronoi diagram or any variation of this generic model. The tilling of Pinctada nacre does respond to a Voronoi diagram. It is a collection of regions (platelets) that divide up the plane under the form of convex polygons. Each platelet corresponds to one and only one nucleation site. All the points in a platelet are closer to the corresponding nucleation center than to any other center. It is possible to identify the nucleus center of any platelet in mature nacre, considering first the curved growing edges on new platelets of the front (their center is the center of curvature). Then, step by step it is easy to locate the nucleation center of each platelet. One verify that a vertex (triple point) is the center of a circle passing through three nucleation centers; every point on the boundary between two platelets is the center of circle passing through two nucleation centers.

Tablets growth can be computerized by means of a bidimensional model as shown in Fig. 11 . The deviation from an ideal hexagonal shape means that the nucleation location is not as perfectly repeated as in a lattice: this is simulated in Fig. 11. In Fig. 11A, nucleation sites locate on an hexagonal array, thus Voronoi cells turn into perfect hexagons. In Fig. 11B the same amount of nuclei was used but with a small deviation from the plane lattice. As a result, the standard deviation of the tablets size increases and the shape turns into more realistic polygons sometimes with five or seven (or more sides). A more sophisticated model is required to take in account the real polygons shape and the progressive start of nucleation with the front advance.

\section{Discussion}

\subsection{The stairs-like front of bio-mineralization}

This work confirms that the front of bio-mineralization in molluscs like Pinctada adopts a unique feature: the stairs-like front, already well accepted by the community (Wada, 1961). Pinctada sheet-nacre growth is not a cycled mechanism row-by-row as in columnar nacre (Nakahara et al., 1982 and Wise, 1970). This evidence of the simultaneous growth of nacreous layers is in agreement with cross-sections obtained by equivalent techniques by other researchers (Nakahara, 1991, Towe and Hamilton, 1968 and Wada, 1972). Its role is fundamental : nacre is growing simultaneously everywhere in the inner surface of the shell. That is the case for the development stages observed starting at the hatching stage, after the metamorphosis of the oyster (i.e., 1 month) until the adult stage (Mao Che et al., 2001). These authors have clearly shown (on the shell-side) that stairs-like growing was seen to be a constant factor of the mineralization, whatever the zone in the shell, i.e., nacre growing parallel to the edge, the finger-print-like nacre in the middle of the shell or in the thickening zones with the "ascending spirals" observed by Wada (1961). The simultaneous growth of layers of nacre allows the growth of the shell in length and in thickness.

What has newly appeared with the first images of the "stairs-like" front of bio-mineralization of sheet nacre, is the hypothesis that the offset provided by this feature is responsible for the dynamics and the interrelationship of different processes, discussed below.

\subsection{Compartment theory}

The experimental evidence obtained in the present work concerns the first picture of nacre layer just before it transforms into bio-aragonite. It furnishes many additional arguments in favor of the compartment theory described by Bevelander and Nakahara (1969). 
It is not clear whether the space between the crystals was occupied by solution or by a macromolecular gel medium that would be penetrated (or not) by the embedding material as a solution. The only evidence is the existence of a compartment under the form of a film, that has to be shaped to materialize the new layer. Shaping can only be possible with a viscous or gel medium. Thanks to the offset, the underlying layer is hard enough to mould the film on one face, squeezed by the mantle in the opposite one.

\subsection{How extrapallial fluid takes on individual characteristic as a compartment?}

The existence of an envelope with a fibril reticulation in mollusc was shown by Grégoire (1962). Bevelander and Nakahara (1969) first postulated that this envelope is condensed from the fluid under the form of $\beta$-chitin and other insoluble organic constituents. Later, they demonstrated the universal presence of this envelope associated with bio-mineralization (Bevelander and Nakahara, 1991). The formation of the envelope by polymerization of the hydrophobic material may be the first step of the self-ordering process of the nacre layer. This envelope is supposed to be the fibrous array (cobweb) observed as the framework upon which any new crystal nucleates (Fig. 10). SEM observations illustrated by Fig. 10 were made after dipping the animal in alcohol, removing gently the soft tissues, drying and gold-coating the shell. There is no special fears about possible artefacts. On shell side, the nuclei are stuck on a fiber network insoluble in alcohol and the simpler hypothesis is to consider this layer as the $\beta$ chitin layer.

Then, the film individualizes on the mantle side. There is only indirect evidence for that. As shown by Wada, nucleation takes place on shell side as hemi-spherical clusters. Very soon the tablets are cylinders which have acquired their final thickness. (This is well known from previous authors.) This implies that the other compartment boundary, on mantle side, is materialized to stop the growth in thickness. The development of a chitin network is a realistic hypothesis.

\subsection{External constraints}

Each aragonite tablet is mono-nucleated. It is possible to assert that nucleation occurs, in time, at the level where the platelets of the underlying row, get in contact to each other. Also, the majority of nucleation sites locates in the vicinity of the intercrystalline boundary between two tablets of the underlying layer. What is systematically observed is the presence of the alveolar layer under the tablets. This layer is likely connected with the intercrystalline matrix of the underlying row or is nearby. The following model can be conjectured from these observations. As soon as this hydrophobic intercrystalline matrix seals two neighboring platelets, it crosses the fibrous array to extend at the bottom surface of the overlying row. It is supposed to grow onto the cobweb of insoluble fibers limiting the superior compartment still viscous. The development of the alveolar matrix could be the necessary condition for nucleation to occur, but evidently not sufficient. The reason is that nucleation proceeds at the level of two platelets boundary, but not systematically. As a summary, extension of this matrix coming via the intercrystalline zone from the underlying row, could be the necessary condition for nucleation to proceed, carrying the crystallographic orientation by an heteroepitaxic mechanism in the same way. 


\subsection{Self-ordering mechanism within the film}

For the first time, it is possible to count exactly the amount of nuclei with these protocols and to follow the growth of the tablets within the compartment. An important point in this work is the Voronoi cell-type ordering around each nucleation site and the progressive mineralization in a continuous process from the fluid to the bio-mineral. The nacre layered structure is developed by a sequence of events (Fig. 12) resulting as a Voronoi-type 2D arrangement. This means that their shape cannot be controlled by the aragonite lattice growth as for a single crystal. At the tablet scale, the shape results from an aggregation-like process of smaller "crystallites." Even if they behave as a single crystal under electron diffraction, tablets are "composite" or polycrystalline structures; this is at least, a reasonable hypothesis to account for the perfect tiling of the space by irregular polygonal platelets with a single-crystal behavior.

\section{References}

Belcher et al., 1996 A.M. Belcher, X.H. Wu, R.J. Christensen, P.K. Hansma, G.D. Stucky and D.E. Morse, Control of crystal phase switching and orientation by soluble mollusc-shell proteins, Nature 381 (1996), pp. 56-58.

Bevelander and Nakahara, 1969 G. Bevelander and H. Nakahara, An electron microscope study of the formation of the nacreous layer in the shell of certain bivalve mollusks, Calcif. Tissue Res. 3 (1969), pp. 84-92.

Bevelander and Nakahara, 1991 G. Bevelander and H. Nakahara, Compartment and envelope formation in the process of biological mineralization In: H. Nakahara, Editors, Mechanisms and Philogeny of Mineralization in Biological Systems, Springer-Verlag, Tokyo (1991), pp. $19-27$.

Caseiro, 1995 J. Caseiro, Evolution de l'épaisseur des dépôts de matériaux organiques et aragonitiques durant la croissance des perles de Pinctada margaritifera, C. R. Acad. Sci. Paris 321 (1995), pp. 9-16.

Falini et al., 1996 G. Falini, S. Albeck, S. Weiner and L. Addadi, Control of aragonite or calcite polymorphism by mollusk shell macromolecules, Science 271 (1996), pp. 67-69.

Feng et al., 1999 Q.L. Feng, H.B. Li, F.Z. Cui and H.D. Li, Crystal orientation domains found in the single lamina in nacre of the Mytilus edulis shell, Mater. Sci. Lett. 18 (1999), pp. 15471549 .

Grégoire, 1962 C. Grégoire, On the submicroscopic structure of the Nautilus shell, Bull. Inst. R. Sci. Nat. Belg. 38 (1962), pp. 1-71.

Levi-Kalisman et al., 2001 Y. Levi-Kalisman, G. Falini, L. Addadi and S. Weiner, Structure of the nacreous organic matrix of a bivalve mollusk shell examined in the hydrated state using Cryo-TEM, J. Struct. Biol. 135 (2001), pp. 8-17.

Mao Che et al., 2001 L. Mao Che, S. Golubic, T. Le Campion-Alsumard and C. Payri, Developmental aspects of biomineralization in the Polynesian pearl oyster Pinctada margaritifera var. cumingii, Oceanol. Acta 24 (2001), pp. 37-49. 
Nakahara et al., 1982 H. Nakahara, G. Bevelander and M. Kakei, Electron microscopic and amino acid studies on the outer and inner shell layers of Haliotis rufescens Venus, Japan, $J$. Malacol. 41 (1982), pp. 33-46.

Nakahara, 1991 H. Nakahara, Nacre formation in bivalve and gastropod mollusks In: Suga and Nakahara, Editors, Mechanisms and Philogeny of Mineralization in Biological Systems, Springer-Verlag, Tokyo (1991) (Chapter 4.2).

Naslain et al., 1998 Naslain, R., Pailler, R., Bourrat, X., Heurtevent, F., 1998. Mimicking the layered structure of natural shells as a design approach to fiber-matrix interface in CMCs. in: Girelli-Visconti, J. (Ed.), Proceeding of the ECCM-8, vol 4. Woodhead Publ., Abington, Cambridge, UK, pp. 191-199.

Schmidt, 1924 N.J. Schmidt, Die Bausteine des Tierkörpers in polarisierten Lichte, Cohen, Bonn (1924).

Simkiss and Wilbur, 1989 K. Simkiss and K.M. Wilbur, Biomineralization, Academic Press, San Diego (1989).

Smith, 1998 B.L. Smith, Studying shells: a growth industry, Chem. Ind. (1998), pp. 649-653.

Towe and Hamilton, 1968 K.M. Towe and G.H. Hamilton, Ultrastructure and inferred calcification of the mature and developing nacre in bivalve mollusks, Calcif. Tissue Res. 1 (1968), pp. 306-318.

Wada, 1961 K. Wada, Crystal growth of molluscan shells, Bull. Nat. Pearl Res. Lab. 36 (1961), pp. 155-156.

Wada, 1972 K. Wada, Nucleation and growth of aragonite crystals in the nacre of some bivalve molluscs, Biomineralization 6 (1972), pp. 141-159.

Watabe, 1965 N. Watabe, Studies on shell formation, XI crystal-matrix relationships in the inner layers of mollusk shells, J. Ultrastruct. Res. 12 (1965), pp. 351-370.

Weiner and Traub, 1984 S. Weiner and W. Traub, Macromolecules in mollusc shells and their functions in biomineralization, Philos. Trans. R. Soc. Lond. B Biol. Sci. 304 (1984), pp. 425434.

Wise, 1970 S.W. Wise, Microarchitecture and mode of formation of nacre (mother of pearl) in Pelecypods, Gastropods, and Cephalopods, Eclogae. Geol. Helv. 63 (1970), pp. 775-797. 


\section{Figures}
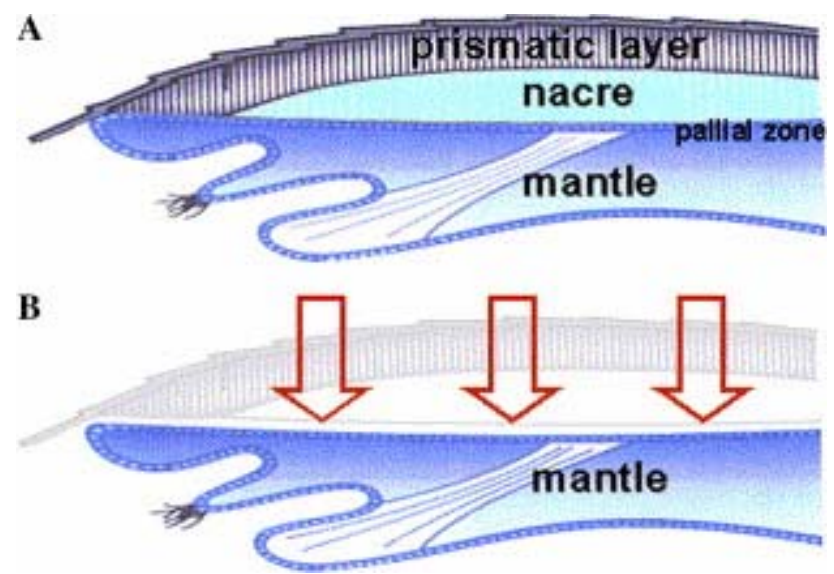

Fig. 1. Schematic showing in (A): a partial section of the animal after mounting in methyl methacrylate (protocol 1) and the pallial zone between the mantle and the nacre, and (B): the fracture surface imaged by SEM on mantle side (empty arrows: SEM incident electrons).

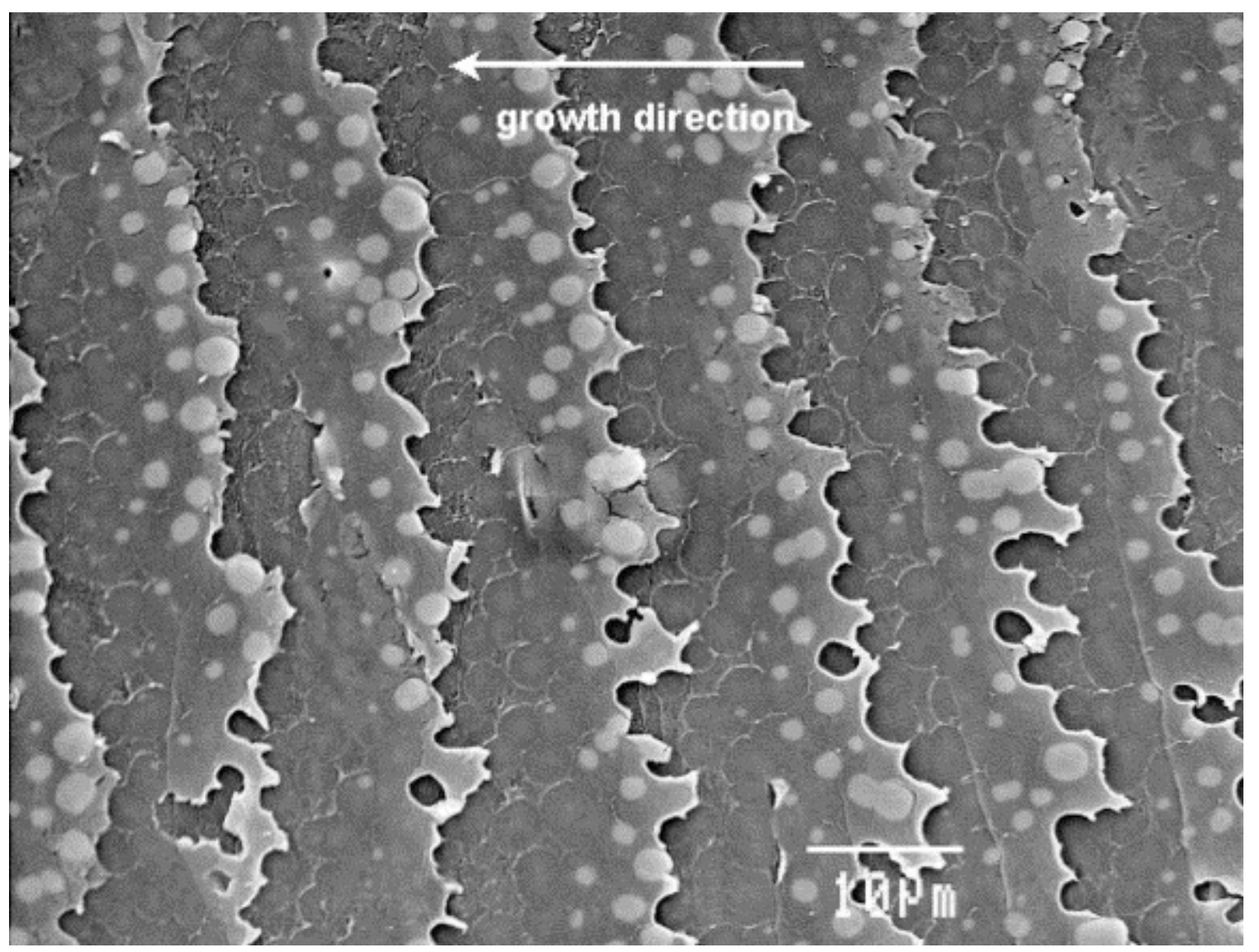

Fig. 2. Incipient nacre layers at the surface of the mantle: fracture surface after fixing, mounting and removal of the shell of the oyster (protocol 1, SEM). The round tablets (lightgrey) are incipient bio-aragonite platelets. 


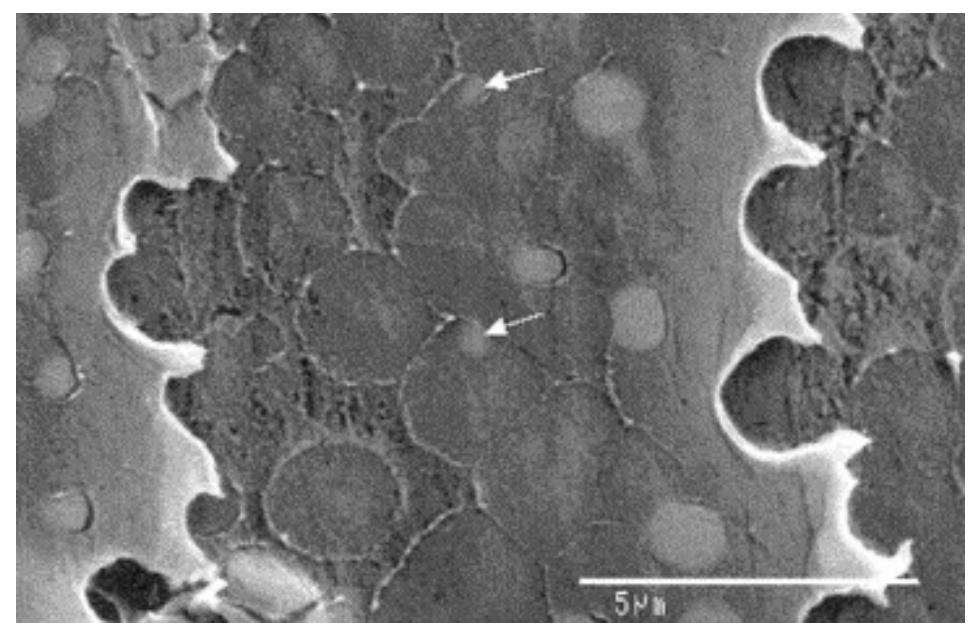

Fig. 3. Same image as Fig. 2, at higher magnification. The imprints are the traces left by tablets already nearly developed in the underlying one, removed with the shell. (Arrows point nuclei at the level of the intercrystalline limit between two tablets of the underlying row.)

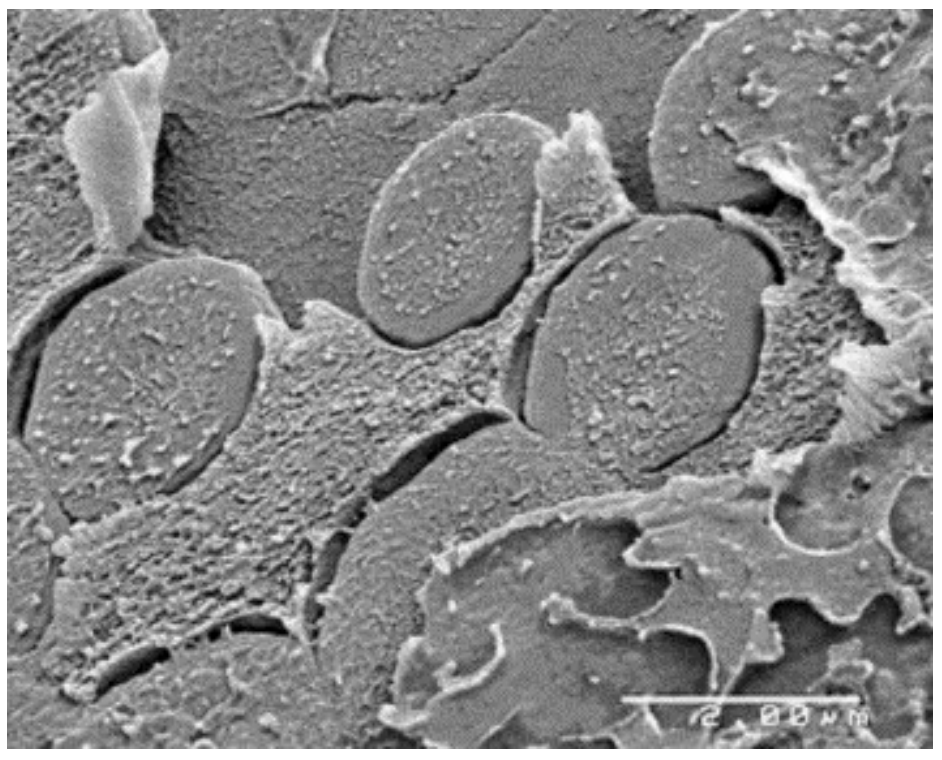

Fig. 4. Incipient nacre on the shell side: detail of the fracture surface revealing cylindrical nuclei (protocol 1, SEM). 


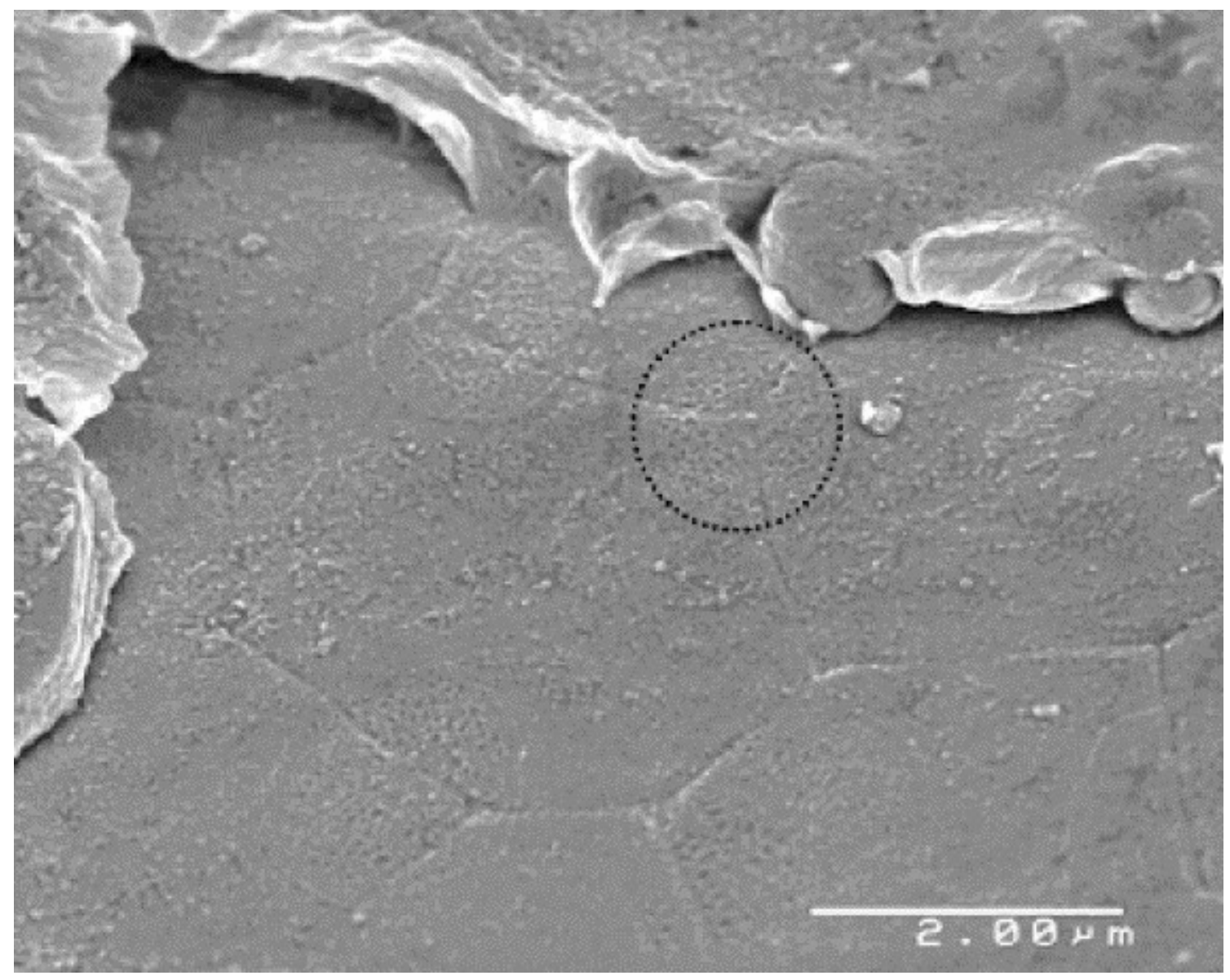

Fig. 5. Incipient nacre on the shell side : imprints that evidence the trace of growing nuclei remained on the other side (protocol 1, SEM; square: trace enlarged in Fig. 6).

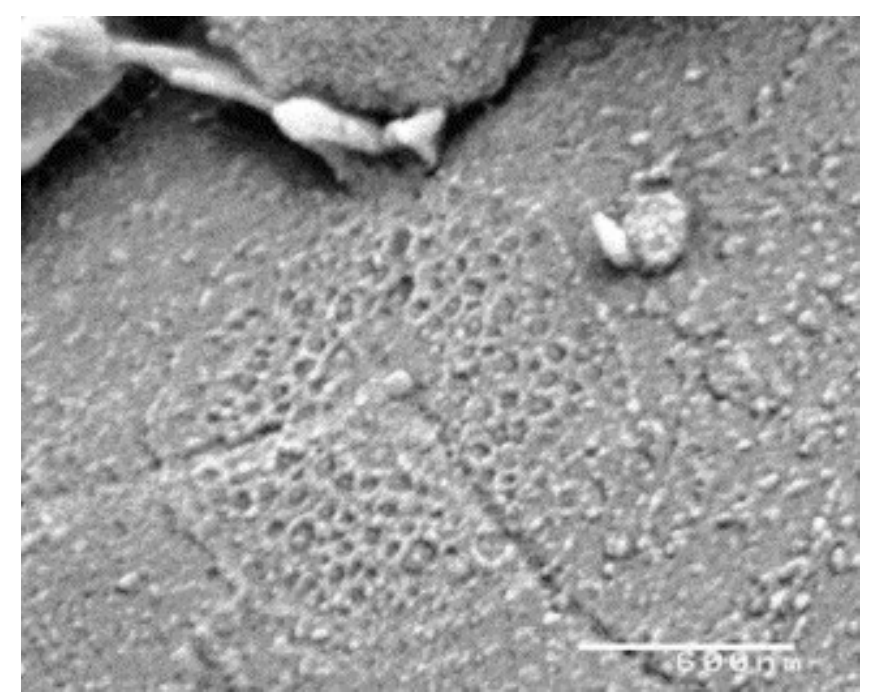

Fig. 6. Part of Fig. 5, high magnification of the imprint: organic alveolar layer extending from a triple point under the growing tablet (removed). 


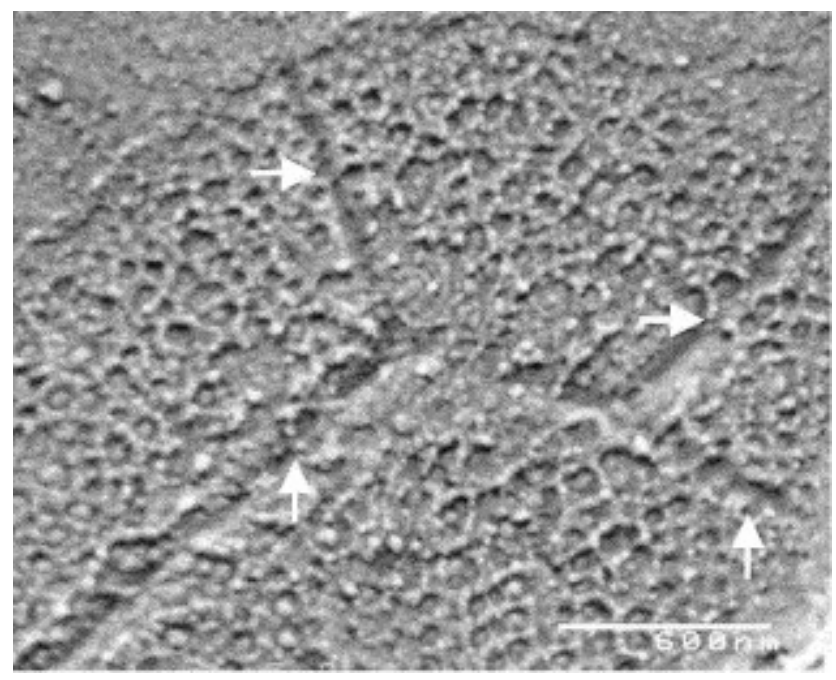

Fig. 7. Part of Fig. 5 with detail of the alveolar layer. (Arrows) Possible relationship with the intercrystalline matrix of the underlying row.
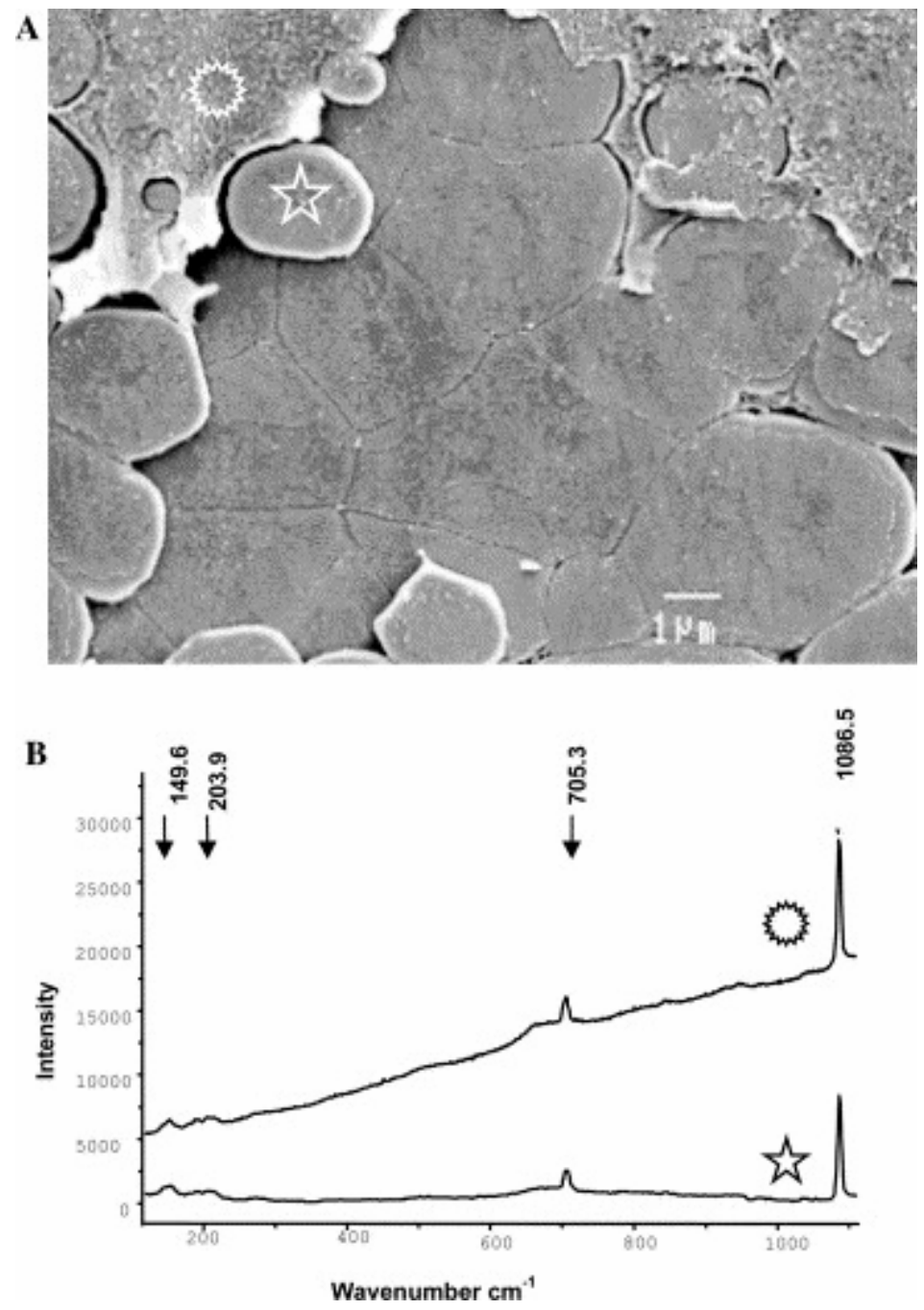

Fig. 8. Raman microscopic characterization of a nucleus (star) and the film (circle) on the shell side (protocol 1): (A) analyses location imaged by SEM and (B) Raman spectra. The film exhibits the same aragonite peaks but with an increasing background of fluorescence. 


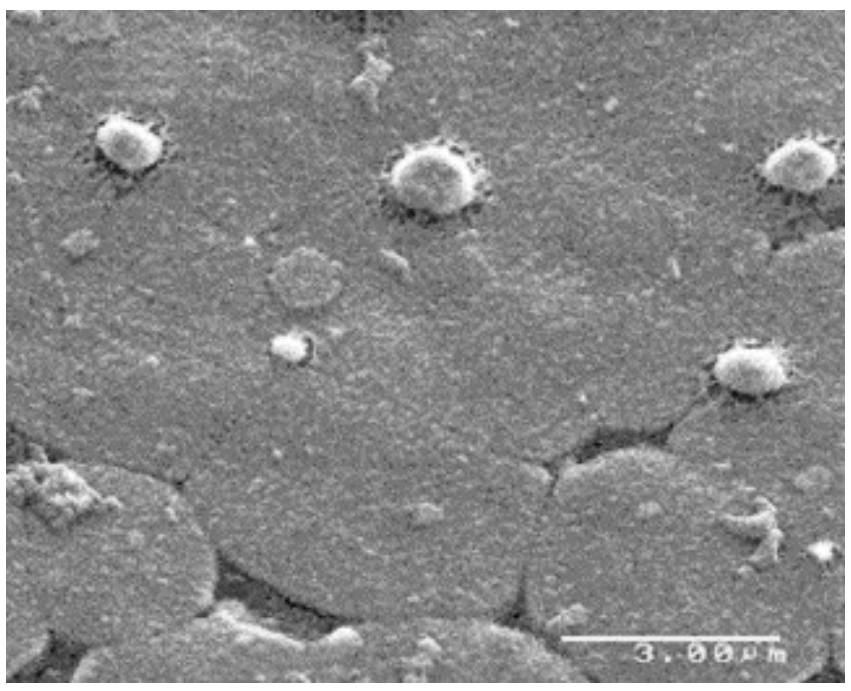

Fig. 9. Direct observation of the shell after the animal was sacrificed in alcohol and the soft tissues removed (protocol 2). Note the size of the nuclei which remain stuck on the shell with this protocol.

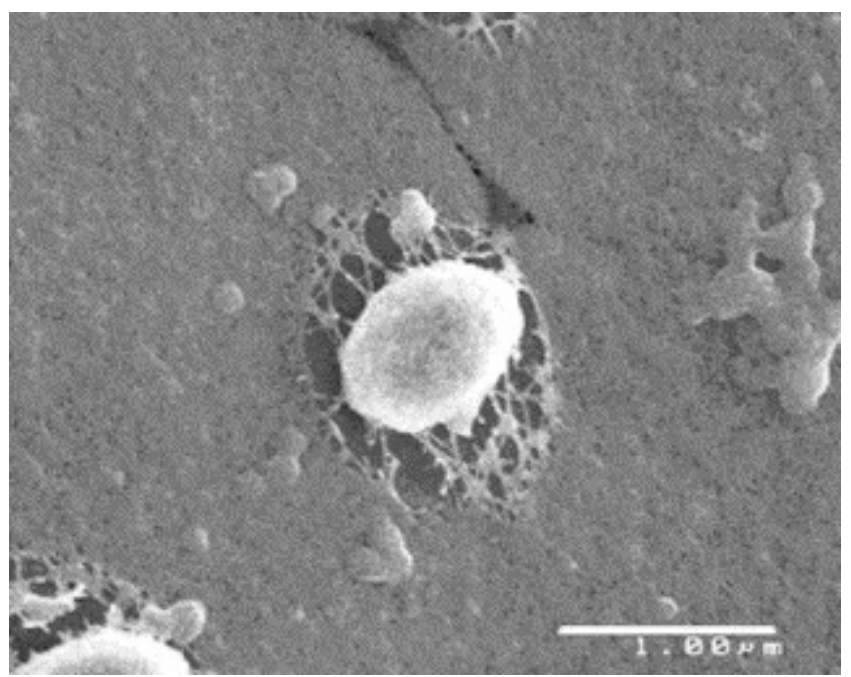

Fig. 10. Detail of Fig. 9: nucleus growing on the cobweb-like envelope of the compartment.
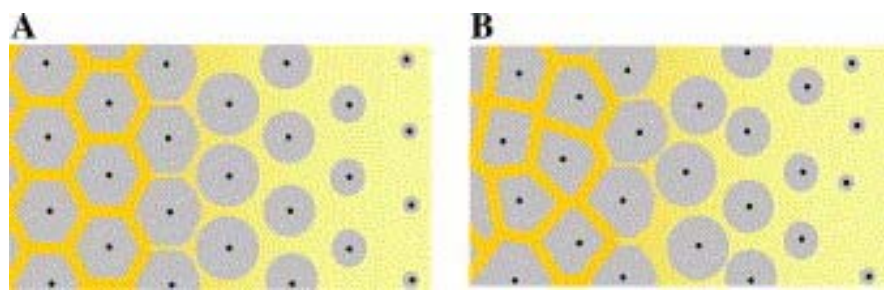

Fig. 11. Modelization of the front of mineralization within the film of extrapallial fluid: (A) a Voronoi diagram for a plane lattice of nuclei; (B) a more realistic case with the same amount of nuclei but less well ordered. 


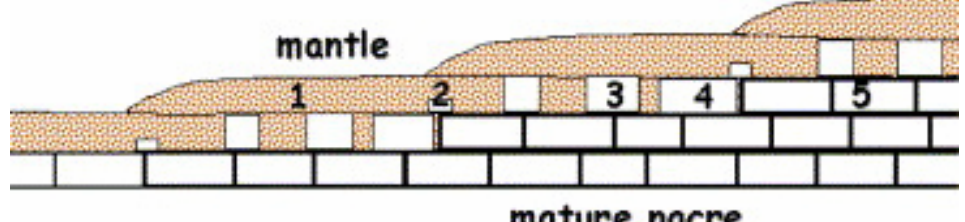

Fig. 12. Model for the stairs-like mineralization front in sheet nacre. It shows the simultaneous multilayered growth of shell: (1) shaping of the fluid as a film (opened compartment), (2) nucleation of tablets, (3) growth of cylindrical platelets, (4) polygonalization, and (5) mature nacre. 